\title{
A SLICE OF TIME
}

\section{You must remember this ...}

\section{BY JEFF HECHT}

$\mathrm{T}$ he Oligarch sitting behind the vast and finely polished desk of genuine red mahogany looked very small or very far away or both. It had taken me a long time to get this far, and I knew that I needed to wait for her to speak.

"I understand that you have something interesting to offer me," she said. My eyes could not focus sharply on her face, but I could see her lips move. Her voice sounded so perfect it had to be synthesized. My ears could not tell from what direction the words really came, but I had expected something like that.

"I have a slice of time," I said, pausing for effect. "It is a very special slice that I think would interest you."

"A slice of time," she said, as if turning the words over to inspect them. "How do you slice time? Across the whole Universe, or across some little segment?"

Perceptive, I thought. And probing. "Only across the portion of the Universe that you affect," I answered. As an Oligarch, she affected all that humanity could reach, but our part of the Universe was very small. Like the rest of us, she had no way to the stars. Our ancestors had studied them for untold millennia, and had even seen their planets. Yet in the Age of the Oligarchs we know our limits. The stars are but bright spots in the sky that we can see but never touch.

Her eyes probed me. I wondered where she really was and how many layers of simulation there were between us. She was not an original Oligarch; they had lived and died before the later Oligarchs had learned how to extend their lives almost indefinitely. Their minds were copied into simulations, and their bodies put into near-immortal suspension, to be disturbed only when the simulations could not answer. Otherwise, their subordinates ruled, consulting with the simulations, until it came time for the subordinates themselves to be suspended, and for their subordinates to rule.

I had spent months showing my slice of
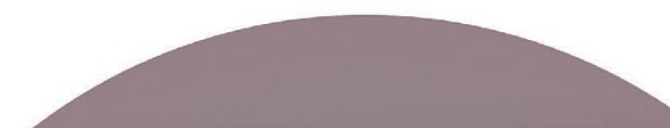

ered. "Young, perhaps four or five, walking along a stream in a little mountain valley, listening to the water tumble over the rocks on a sunny late summer afternoon. You were happy and free. It was not an easy time to find."

"Show me", she said. I opened the slice of time, spreading it wide on the vastness of the table. It unfolded larger and larger, taking on more reality as it grew. The water and the rocks sparkled in the sunlight that came through the leaves; the air was warm and fresh. I could feel a light breeze and hear the water tumbling over the rocks in the stream. It had taken me many years to capture that slice of time.

More time passed, as I had expected. Latency, the masters of the machines call it. The time information takes to get from here to there and back. The time for the simulation to pass my offer to the ancient human somewhere behind the layers of simulations and human subordinates devoted to preserving their own lucrative servitude, and the time for her to send her response back to the simulation. They might delay but they had to obey; the ultimate control was hers. Was supposed to be hers, I told myself, hoping that she was not just dust inside an empty shell somewhere deep inside the vastness of the Oligarchy.

"You may have your price," came her voice, suddenly younger and full of hope.

I smiled. "You will enjoy it," I said, hoping that neither of us was lying. For my price was to be placed high in the line of her subordinates, just below the lowest level that had been frozen into the ranks of power and simulation. There I would hold the power of trusteeship in her name and in the names of all the higher subordinates in the frozen hierarchy of power, until the fullness of age came upon me and I sought my own slice of time.

Jeff Hecht is Boston correspondent for New Scientist and a contributing editor to Laser Focus World. 